\title{
Edinburgh primary care depression study: treatment outcome, patient satisfaction, and cost after 16 weeks
}

\author{
Allan I F Scott, Christopher P L Freeman
}

\begin{abstract}
Objective-To compare the clinical efficacy, patient satisfaction, and cost of three specialist treatments for depressive illness with routine care by general practitioners in primary care.

Design-Prospective, randomised allocation to amitriptyline prescribed by a psychiatrist, cognitive behaviour therapy from a clinical psychologist, counselling and case work by a social worker, or routine care by a general practitioner.
\end{abstract}

Subjects and setting-121 patients aged between 18 and 65 years suffering depressive illness (without psychotic features) meeting the criteria of the Diagnostic and Statistical Manual of Mental Disorders, Third Edition for major depressive episode in 14 primary care practices in southern Edinburgh.

Main outcome measures-Standard observer rating of depression at outset and after four and $\mathbf{1 6}$ weeks. Numbers of patients recovered at four and 16 weeks. Total length and cost of therapist contact. Structured evaluation of treatment by patients at 16 weeks.

Results-Marked improvement in depressive symptoms occurred in all treatment groups over 16 weeks. Any clinical advantages of specialist treatments over routine general practitioner care were small, but specialist treatment involved at least four times as much therapist contact and cost at least twice as much as routine general practitioner care. Psychological treatments, especially social work counselling, were most positively evaluated by patients.

Conclusions-The additional costs associated with specialist treatments of new episodes of mild to moderate depressive illness presenting in primary care were not commensurate with their clinical superiority over routine general practitioner care. A proper cost-benefit analysis requires information about the ability of specialist treatment to prevent future episodes of depression.

\section{Introduction}

A substantial part of the workload of any general practitioner is the management of depression. ${ }^{2}$ Antidepressant drug treatment is the most common treatment for depressive illness used by general practitioners, ${ }^{3}$ although there are only a few placebo controlled trials that support the use of antidepressants in primary care.$^{+6}$ Amitriptyline may be no better than placebo in the milder forms of depression presenting in primary care.

There are other problems about the use of antidepressant drugs in primary care. Some $20 \%{ }^{6}$ to $59 \%^{8}$ of primary care patients prescribed antidepressant drugs stop taking what their doctor prescribed within three weeks. Reasons for this low compliance include spontaneous improvement, the development of unpleasant adverse effects, a failure to appreciate that antidepressant drugs must be taken for several weeks, and a belief that pills are not the answer to depressions associated with stress or adverse life events. ${ }^{8}$ Professional critics suggested that by suppressing distress psychotropic drugs may make it less likely that the sufferer will try to resolve the problem that led to the depression. ${ }^{910}$ General practitioners themselves have been criticised for the use of inadequate doses of antidepressant drugs, ${ }^{8}$ the inappropriate use of anxiolytic drugs, ${ }^{11}$ and a failure to refer patients to social agencies. ${ }^{12}$

Social and relationship problems are prevalent among depressed patients seeing their general practitioner, ${ }^{8} 13-15$ and psychological treatments may be more appropriate than drug treatment. Intervention by a social worker attached to a general practice was shown to be as effective as routine management by general practitioner in young depressed women. ${ }^{12}$ Cognitive behaviour therapy, which relies on problem solving strategies, has been shown to be more effective than antidepressant drug therapy alone $\mathrm{e}^{16}$ and "treatment as usual" 17 in primary care. The investment of time and skill required by both social work intervention and cognitive behaviour therapy is quite unlike the routine management of depressed patients in primary care: most patients see their doctor for less than 10 minutes on the first occasion. ${ }^{18}$ Such investments may be justified if psychological treatments are more clinically effective, more acceptable to patients, or prevent further episodes of depression by helping patients cope better with problems.

Our first aim was to compare the clinical efficacy of the routine management of depressive illness by general practitioner with the clinical efficacy of amitriptyline prescribed by a visiting psychiatrist. Our second aim was to compare routine management with the psychological treatments of case work by a visiting social worker and cognitive behaviour therapy from a visiting clinical psychologist. Treatments for depression are often combined in clinical practice, but we felt it was important to determine which, if any, of these specialist treatments were superior to routine general practitioner care. Complementary aims were the comparison of how much time and money each treatment cost and how they were valued by patients themselves.

\section{Methods}

\section{PATIENTS SELECTION}

Sixty three general practitioners from 14 primary care practices (including socially deprived parts of the city as well as more affluent suburbs) in the southern half of Edinburgh agreed to refer to the study coordinator any patient they had seen, aged between 18 and 65 years, about to start treatment for depressive
Correspondence to: $\mathrm{D}$ BM7 1992;304:883-7 
illness. Potential patients were interviewed at the practice by the trained lay coordinator, who made use of a structured clinical interview prepared for use with the Diagnostic and Statistical Manual of Mental Disorders, Third Edition (DSM-III). The primary inclusion criterion was that the patient met the DSMIII criteria for major depressive episode ${ }^{19}$ - namely, dysphoric mood accompanied by at least four biological features of depression, such as poor appetite, sleep difficulty, loss of energy, psychomotor changes, or impaired concentration for at least two weeks. Exclusion criteria were the presence of delusions, depression secondary to schizophrenia, marked suicidal risk, and a recent history of alcohol or drug abuse. Thirty seven general practitioners referred 194 patients between March 1987 and March 1989. One hundred and forty three patients met the entry criteria, but only 121 agreed to take part in the study. When an explicit reason was given for not agreeing to take part a reluctance to be treated with drugs was the most common.

Eligible patients who gave consent were randomly allocated to treatment using a system of sealed envelopes prepared before the study began. Once 30 patients had been allocated to any one treatment the lay coordinator ignored further allocation to that treatment and opened one or more further envelopes until one of the three other treatments came up and so on. This procedure was involved in the allocation of the last seven patients.

\section{TREATMENTS}

All treatments were provided in primary care and lasted up to 16 weeks. Patients offered routine general practitioner care were asked to make an appointment with their own general practitioner for treatment. The research staff made no recommendations about treatment, but inclusion in the study confirmed a diagnosis of depression. General practitioners were asked to manage each case as he or she would normally, and this included referral to other agencies.

The research psychiatrist who prescribed amitriptyline informed patients about the nature of depressive illness, that improvement can be expedited in most cases by the prescription of an antidepressant drug over a period of several weeks, and possible adverse effects. No other psychological interventions were used. Amitriptyline was prescribed starting at a dose of $50-75 \mathrm{mg}$ daily and gradually increasing to at least $150 \mathrm{mg}$ daily. Patients were seen weekly for the first two weeks and then fortnightly or monthly thereafter as required. No additional psychotropic drugs were prescribed.

Cognitive behaviour therapy was provided by research clinical psychologists, both of whom had worked as senior clinical psychologists, then trained in the specialist techniques as described by Beck et al. ${ }^{20}$ Appointments usually lasted 50 minutes and were weekly at the start of treatment and at variable intervals

TABLE I-Demographic details of patients $(n=121)$ by treatment group. Except where stated otherwise figures are numbers (percentages) of patients

\begin{tabular}{lcccc}
\hline & \multicolumn{4}{c}{ Treatment } \\
\cline { 2 - 5 } & $\begin{array}{c}\text { Amitriptyline/ } \\
\text { psychiatrist }(\mathbf{n}=31)\end{array}$ & $\begin{array}{c}\text { Cognitive therapy } \\
(\mathbf{n}=30)\end{array}$ & $\begin{array}{c}\text { Social work } \\
\text { counselling }(\mathbf{n}=30)\end{array}$ & $\begin{array}{c}\text { General practitioner } \\
\text { care }(\mathbf{n}=30)\end{array}$ \\
\hline Men:women & $12: 19$ & $5: 25$ & $5: 25$ & $8: 22$ \\
Mean(SD) age (years) & $30 \cdot 6(10 \cdot 8)$ & $28 \cdot 8(8 \cdot 1)$ & $36 \cdot 2(14 \cdot 2)$ & $31 \cdot 6(10 \cdot 7)$ \\
Cohabiting & $12(39)$ & $13(43)$ & $13(43)$ & $11(37)$ \\
Social class: & $12(39)$ & $8(27)$ & $5(17)$ & $7(23)$ \\
A + B & $15(48)$ & $16(53)$ & $20(67)$ & $20(67)$ \\
C $_{1}+C_{2}$ & $4(13)$ & $6(20)$ & $5(17)$ & $3(10)$ \\
D + E & $20(64)$ & $22(73)$ & $24(80)$ & $22(73)$ \\
Work status: & $3(10)$ & $3(10)$ & $2(7)$ & $3(10)$ \\
$\quad$ Employed & $8(26)$ & $5(17)$ & $4(13)$ & $5(17)$ \\
Unemployed & & & & \\
Housewife or other & & &
\end{tabular}

thereafter. Specific techniques included training in self monitoring, the identification of automatic thoughts and basic assumptions, and testing out new ways of coping and behaving between sessions. No psychotropic drugs were prescribed.

Social work intervention was carried out by two qualified social workers, both of whom had previous experience of working with medical and psychiatric hospital patients. A detailed social assessment was carried out that led over the first one or two sessions to the construction of a problem list and thereafter an intervention programme. Initial sessions were weekly but thereafter sessions were flexible. Strategies included support by encouragement and listening, help to understand feelings, practical advice, rehearsing events, support by the exercise of authority, advocacy on the patient's behalf, arranging social support or holidays, and marital or family meetings if appropriate.

\section{ASSESSMENTS}

Patients were interviewed by independent trained raters on the day they started treatment (week 0 ) and then after four and 16 weeks. At week 0 the rater collected background demographic (including social class $^{21}$ ) and clinical information. At each assessment the severity of depression was recorded by the rater using the Hamilton rating scale for depression..$^{22}$ Raters were blind to treatment allocation at week 0 , but it is likely that patients made them aware of their treatment at later meetings. At 16 weeks the independent raters gave the patients a questionnaire to evaluate five aspects of their treatment on a four point scale ("yes, definitely" to "no, definitely not"). Patients treated by psychotropic drugs were questioned about their compliance (actual dose taken and length of intake). Therapists recorded the number and length of all appointments. Data on general practitioner management were recorded by the raters from all available sources, chiefly patients and primary care case notes. The costs of therapists' time and hospital services were based on prices in 1986-7. ${ }^{23}$ Drug costs were based on the pricing of NHS prescriptions dispensed in August $1987 . .^{24}$

\section{ANALYSIS}

Comparisons among the treatment groups were made by one way analysis of variance for continuous variables and $\chi^{2}$ (or Fisher's exact) test for discontinuous variables. Recovery was defined a priori as a Hamilton score less than $7 .{ }^{25}$ An "intention to treat" analysis was used in the comparison of recovery ratesthat is, patients who refused to continue treatment were classified as "not recovered." Differences in depression ratings and recovery rates were assessed using $95 \%$ and $99 \%$ confidence intervals.

\section{Results}

\section{RANDOMISATION}

The treatment groups were similar in most demographic and clinical details (tables I and II). Only two $(7 \%)$ of the patients randomised to cognitive behaviour therapy had a history of treatment for depressive illness, which was a much smaller proportion than in the other treatments, and the proportion of men among the patients allocated to amitriptyline was twice as great as among those allocated to cognitive therapy or social work counselling.

\section{PATIENTS REFUSING TREATMENT}

Five of the seven patients who refused to start specialist treatment after randomisation were in the group allocated to amitriptyline prescribed by the psychiatrist. One patient randomised to routine general practitioner care did not make an appointment to see 
TABLE II - Clinical details of patients $(n=121)$ by treatment group. Except where stated otherwise figures are numbers (percentages) of patients

Treatment

\begin{tabular}{|c|c|c|c|c|}
\hline & $\begin{array}{c}\text { Amitriptyline/ } \\
\text { psychiatrist }(n=31)\end{array}$ & $\begin{array}{c}\text { Cognitive therapy } \\
\qquad(\mathbf{n}=30)\end{array}$ & $\begin{array}{c}\text { Social work } \\
\text { counselling }(n=30)\end{array}$ & $\begin{array}{c}\text { General practitioner } \\
\text { care }(n=30)\end{array}$ \\
\hline $\begin{array}{l}\text { Median length of episode } \\
\text { (weeks) }\end{array}$ & $13 \cdot 5$ & $18 \cdot 0$ & $12 \cdot 0$ & $10 \cdot 0$ \\
\hline Melancholia (DSM-III) & $5(16)$ & $4(13)$ & $5(17)$ & $8(26)$ \\
\hline Previous treated episode & $8(26)$ & $2(7)^{\star}$ & $12(40)$ & $10(33)$ \\
\hline $\begin{array}{l}\text { First degree relative with } \\
\text { history of depressive } \\
\text { illness }\end{array}$ & $16(52)$ & $11(37)$ & $14(47)$ & $13(43)$ \\
\hline $\begin{array}{l}\text { Concurrent physical } \\
\text { illness }\end{array}$ & $5(16)$ & $3(10)$ & $5(17)$ & $9(30)$ \\
\hline
\end{tabular}

^Significantly different $(\mathrm{p}<0.05)$ from social work counselling and general practitioner care (Fisher's exact test).

TABLE III - Severity of depression measured by Hamilton scores throughout treatment

\begin{tabular}{|c|c|c|c|c|}
\hline & \multicolumn{4}{|c|}{ Treatment } \\
\hline & $\begin{array}{c}\text { Amitriptyline/ } \\
\text { psychiatrist }(n=26)\end{array}$ & $\begin{array}{l}\text { Cognitive therapy } \\
(\mathbf{n}=29)\end{array}$ & $\begin{array}{c}\text { Social work } \\
\text { counselling }(n=29)\end{array}$ & $\begin{array}{l}\text { General practitioner } \\
\text { care }(n=29)\end{array}$ \\
\hline \multicolumn{5}{|c|}{ Week 0} \\
\hline $\begin{array}{l}\text { Mean (SD) Hamilton } \\
\text { score }\end{array}$ & $18 \cdot 2(6 \cdot 6)$ & $18 \cdot 3(5 \cdot 4)$ & $15 \cdot 7(5 \cdot 7)$ & \multirow[t]{2}{*}{$19 \cdot 7(5 \cdot 4)$} \\
\hline $\begin{array}{l}95 \% \text { Confidence interval } \\
\text { of difference from } \\
\text { general practitioner care } \\
\text { Significance }\end{array}$ & $\begin{array}{l}-4 \cdot 8 \text { to } 1 \cdot 6 \\
\text { NS }\end{array}$ & $\begin{array}{l}-4 \cdot 4 \text { to } 1 \cdot 4 \\
\text { NS }\end{array}$ & $\begin{array}{l}-7 \text { to }-1 \cdot 1 \\
\mathrm{p}<0.05\end{array}$ & \\
\hline & & Week 4 & & \multirow{3}{*}{$12 \cdot 9(6 \cdot 1)$} \\
\hline $\begin{array}{l}\text { Mean (SD) Hamilton } \\
\text { score } \\
95 \% \text { Confidence interval }\end{array}$ & $9 \cdot 3(6 \cdot 0)$ & $11 \cdot 9(8 \cdot 4)$ & $11 \cdot 7(7 \cdot 1)$ & \\
\hline $\begin{array}{l}\text { of difference from } \\
\text { general practitioner care } \\
\text { Significance }\end{array}$ & $\begin{array}{c}-6.9 \text { to }-0.3 \\
p<0.05\end{array}$ & $\begin{array}{c}-4 \cdot 9 \text { to } 2 \cdot 9 \\
\text { NS }\end{array}$ & $\begin{array}{l}-4 \cdot 7 \text { to } 2 \cdot 3 \\
\text { NS }\end{array}$ & \\
\hline & & Week 16 & & \multirow{3}{*}{$8 \cdot 4(7 \cdot 5)$} \\
\hline $\begin{array}{l}\text { Mean (SD) Hamilton } \\
\text { score } \\
95 \% \text { Confidence interval }\end{array}$ & $8 \cdot 0(8 \cdot 5)$ & $6 \cdot 7(6 \cdot 1)$ & $4 \cdot 9(5 \cdot 5)$ & \\
\hline $\begin{array}{l}\text { of difference from } \\
\text { general practitioner care } \\
\text { Significance }\end{array}$ & $\begin{array}{c}-4 \cdot 8 \text { to } 3 \cdot 9 \\
\text { NS }\end{array}$ & $\begin{array}{l}-5 \cdot 3 \text { to } 1 \cdot 9 \\
\text { NS }\end{array}$ & $\begin{array}{c}-7 \cdot 0 \text { to } 0.0 \\
p=0.05\end{array}$ & \\
\hline
\end{tabular}

TABLE IV-Clinical efficacy of treatments measured by rate of recovery ${ }^{\star}$

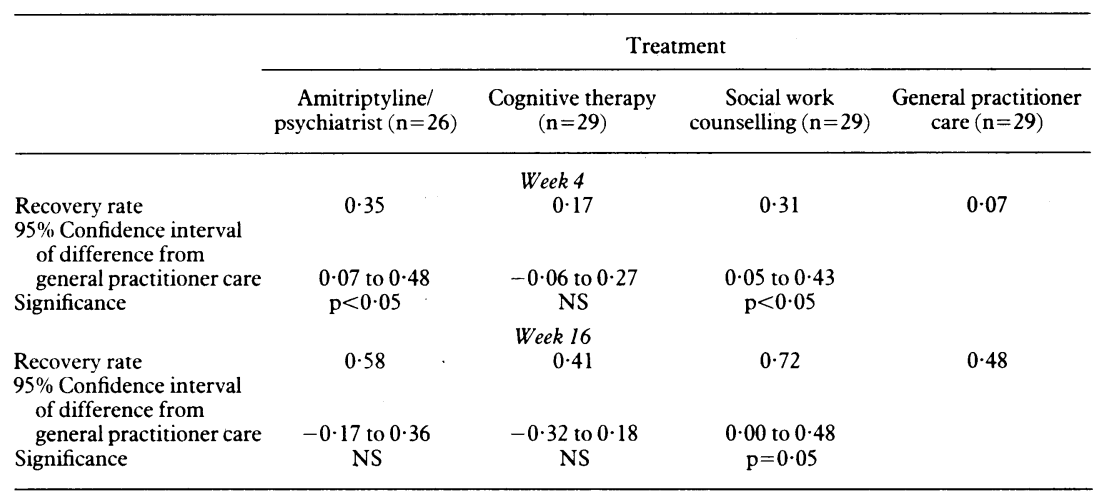

${ }^{\star}$ Recovery was defined as Hamilton score less than $7 .{ }^{2}$ Patients who refused to continue treatment were classified as "not recovered."

her general practitioner. Six of the eight patients who refused to continue specialist treatment received cognitive behaviour therapy. All six were young and from the lower social classes.

\section{PRESCRIPTION AND USE OF PSYCHOTROPIC DRUGS}

Twenty five of the $26(96 \%)$ patients who agreed to accept amitriptyline from the psychiatrist were prescribed at least $150 \mathrm{mg}$ of amitriptyline daily. Eighteen of the $26(69 \%)$ patients took this dose for a minimum of three weeks.

Nineteen of the 29 patients who attended their general practitioner were prescribed an antidepressant drug, but only 14 (48\%) were prescribed a therapeutic dose equivalent to $150 \mathrm{mg}$ amitriptyline and only 13 of the $29(45 \%)$ patients took a therapeutic dose for three weeks. Amitriptyline was prescribed most commonly (13 patients), but lofepramine(four patients), dothiepin (one patient), and mianserin (one patient) were also prescribed. Four patients were prescribed an anxiolytic drug alone-namely, diazepam (two patients), temazepam (one patient), and flupenthixol (one patient). Five patients were not prescribed any psychotropic drugs.

\section{CLINICAL EFFICACY}

The average severity of depression measured by Hamilton score was least in the group treated by social work counselling (table III) and, unlike the other treatment groups, only a minority of patients $(n=11)$ had an initial Hamilton score greater than 16-a common inclusion criterion for outpatient studies of depression. ${ }^{15}$ After four weeks, amitriptyline prescribed by a psychiatrist produced significantly better results than routine general practitioner care in both Hamilton score (table III) and recovery rate (table IV), whereas social work counselling produced a significantly better recovery rate. After 16 weeks only social work counselling was superior to general practitioner care, but twice as many patients who received routine general practitioner care had an initial Hamilton score greater than $16 \quad(n=22)$. Of the more depressed patients, nine out of 11 treated by social work counselling recovered by 16 weeks compared with only nine out of 22 treated by routine general practitioner care (not statistically significant). Both of these patients who did not recover with social work counselling were men. Unfortunately, the number of men in the study was too small to make any firm conclusion about the effect of sex on clinical efficacy.

Of the patients allocated to routine general practitioner care, there was no difference in clinical outcome between those patients who took a therapeutic dose of an antidepressant drug and those who did not.

Clinical efficacy was assessed separately in the 22 patients $(18 \%$ of all patients) who met the DSM-III criteria for melancholia (table V)-that is, a severe form of major depressive episode characterised by pervasive loss of pleasure, early morning wakening, retardation or agitation, weight loss, and inappropriate guilt and believed to be particularly responsive to physical treatment. At both four and 16 weeks the severity of depression measured by Hamilton score was substantially less in the 14 melancholic patients treated by any specialist treatment than in the eight patients treated by their general practitioner. The rate of recovery in patients who received any of the specialist treatments was significantly greater than in those treated by their general practitioner after four weeks. There were too few melancholic patients to compare the clinical efficacy of different specialist treatments, but recovered patients were spread over all three treatment groups.

None of the patients who refused treatment agreed to be reinterviewed, so it was not possible to compare the clinical outcome between patients who completed treatment and those who did not.

\section{THERAPIST CONTACT AND COST}

All specialist treatments involved at least twice as many appointments and from four (amitriptyline/ psychiatrist) to 14 (social work counselling) times more face to face contact than in general practitioner care (table VI). Although both cognitive behaviour therapy and social work counselling involved more face to face contact than amitriptyline treatment from the psychiatrist, the total costs of the three specialist treatments were similar because clinical psychologists and social workers are less expensive to employ by the hour. Face to face contact with the specialist therapists cost about four times as much as the cost of the time the general practitioners themselves spent with the patients. General practitioner care, however, made use of other NHS personnel and resources: three patients were 
referred to and seen at a psychiatric outpatient clinic (staff costs £142), one patient was referred to a psychiatric outpatient clinic and attended a psychiatric day hospital (estimated cost $£ 444$ ), and one patient was referred to a primary care health visitor (£33). If these additional costs are included, then the average cost per patient in general practitioner care rose to $£ 47$, which was still less than half the cost of any of the specialist treatments.

A therapeutic dose of amitriptyline prescribed by the psychiatrist cost $£ 1.48$ for three weeks' treatment. Some general practitioners prescribed newer, more expensive antidepressant drugs, but most prescribed amitriptyline and there was no significant difference in the average cost of three weeks' antidepressant drug treatment from the general practitioners ( 22.48$)$. The average cost of all psychotropic drugs over all patients allocated to general practitioner care was $£ 8.31$ over 16 weeks and $£ 7.28$ in patients allocated to amitriptyline treatment from the psychiatrist (no significant difference). The cost of psychotropic drugs prescribed by general practitioners increased the average cost of

TABLE $\mathrm{v}-$ Severity of illness in melancholic patients $(n=22)$ over 16 weeks

\begin{tabular}{|c|c|c|c|c|}
\hline & $\begin{array}{l}\text { Any specialist } \\
\text { treatment }(n=14)\end{array}$ & $\begin{array}{c}\text { General practitioner } \\
\text { care }(n=8)\end{array}$ & $\begin{array}{l}\text { 95\% Confidence } \\
\text { interval of difference }\end{array}$ & Significance \\
\hline $\begin{array}{l}\text { Mean (SD) Hamilton } \\
\text { score }\end{array}$ & $18 \cdot 5(5 \cdot 1)$ & $\begin{array}{l}\text { Week } 0 \\
23 \cdot 0(4 \cdot 9) \\
\text { Week } 4\end{array}$ & $-9 \cdot 1$ to $0 \cdot 8$ & NS \\
\hline $\begin{array}{l}\text { Mean (SD) Hamilton } \\
\text { score } \\
\text { Proportion of recovered } \\
\text { patients (actual No) }\end{array}$ & $\begin{array}{r}9 \cdot 2(6 \cdot 9) \\
0 \cdot 34(6 / 14)\end{array}$ & $\begin{array}{r}18 \cdot 3(6 \cdot 5) \\
0(0 / 8)\end{array}$ & $\begin{array}{c}-15.4 \text { to }-2.8 \\
0.15 \text { to } 0.68\end{array}$ & $\begin{array}{l}\mathrm{p}<0.01 \\
\mathrm{p}<0.01\end{array}$ \\
\hline $\begin{array}{l}\text { Mean (SD) Hamilton } \\
\text { score } \\
\text { Proportion of recovered } \\
\text { patients (actual No) }\end{array}$ & $\begin{array}{c}3 \cdot 6(5 \cdot 2) \\
0 \cdot 71(10 / 14)\end{array}$ & $\begin{array}{l}\text { Week } 16 \\
13 \cdot 8(10 \cdot 1) \\
0 \cdot 38(3 / 8)\end{array}$ & $\begin{array}{l}-16.9 \text { to }-3.5 \\
-0.07 \text { to } 0.75\end{array}$ & $\begin{array}{c}\mathrm{p}<0.01 \\
\text { NS }\end{array}$ \\
\hline
\end{tabular}

TABLE VI - Length and cost of therapist contact for each treatment. ${ }^{\star}$ Figures are means $(S D)$

\begin{tabular}{lcccc}
\hline & \multicolumn{4}{c}{ Treatment } \\
\cline { 2 - 5 } & $\begin{array}{c}\text { Amitriptyline/ } \\
\text { psychiatrist }(\mathrm{n}=26)\end{array}$ & $\begin{array}{c}\text { Cognitive therapy } \\
(\mathrm{n}=29)\end{array}$ & $\begin{array}{c}\text { Social work } \\
\text { counselling }(\mathrm{n}=29)\end{array}$ & $\begin{array}{c}\text { General practitioner } \\
\text { care }(\mathrm{n}=29)\end{array}$ \\
\hline & & All patients $(n=114)$ & & \\
No of appointments & $8 \cdot 2(4 \cdot 2)$ & $9 \cdot 8(4 \cdot 4)$ & $12 \cdot 8(4 \cdot 2)$ & $4 \cdot 4(2 \cdot 8)$ \\
Minutes of total contact & $237(147)$ & $463(248)$ & $727(238)$ & $50(60)$ \\
Cost (£) of therapist's time & $113(70) \dagger$ & $115(62)$ & $121(40)$ & $26(32) \ddagger$ \\
No of appointments & $8 \cdot 8(3 \cdot 1)$ & Recovered patients $(n=62)$ & $12 \cdot 7(4 \cdot 6)$ & $4 \cdot 6(3 \cdot 0)$ \\
Minutes of total contact & $254(116)$ & $9 \cdot 6(3 \cdot 6)$ & $708(252)$ & $45(45)$ \\
Cost $(£)$ of therapist's time & $120(55)$ & $114(198)$ & $118(42)$ & $24(24)$ \\
\hline
\end{tabular}

^All comparisons gave significant $(p<0.001)$ effects of treatment in one way analysis of variance.

tWhen cost of amitriptyline was included mean cost was $£ 120$.

‡When drug costs were included mean cost was $£ 34$. When use of other NHS staff and resources was also included mean cost was $£ 55$.

TABLE VII - Evaluation of treatment by patients after 16 weeks. ${ }^{\star}$ Except where stated otherwise figures are numbers (percentages) of patients

\begin{tabular}{lcccc}
\hline & \multicolumn{4}{c}{ Treatment } \\
\cline { 2 - 5 } & $\begin{array}{c}\text { Amitriptyline/ } \\
\text { psychiatrist }(\mathrm{n}=22)\end{array}$ & $\begin{array}{c}\text { Cognitive therapy } \\
(\mathrm{n}=23)\end{array}$ & $\begin{array}{c}\text { Social work } \\
\text { counselling }(\mathrm{n}=29)\end{array}$ & $\begin{array}{c}\text { General practitioner } \\
\text { care }(\mathrm{n}=27)\end{array}$ \\
\hline $\begin{array}{l}\text { Almost all needs met } \\
\begin{array}{l}\text { Helped a great deal with } \\
\text { problems }\end{array}\end{array}$ & $7(32)$ & $3(13)$ & $14(48) \dagger$ & $6(22)$ \\
$\begin{array}{l}\text { Very satisfied with amount } \\
\text { of time }\end{array}$ & $11(50)$ & $13(56)$ & $19(66) \ddagger$ & $6(22)$ \\
$\begin{array}{l}\text { Very satisfied overall with } \\
\text { treatment }\end{array}$ & $10(46)$ & $7(30)$ & $14(48)$ & $10(38)$ \\
$\begin{array}{l}\text { Definitely want same } \\
\text { treatment again }\end{array}$ & $10(46)$ & $10(44)$ & $20(69)$ & $13(48)$ \\
$\begin{array}{l}\text { Mean }(\text { SD) cumulative } \\
\text { score on five items } \\
\text { above }\end{array}$ & $15 \cdot 4(3 \cdot 4)$ & $6(26)$ & $15(52) \ddagger$ & $4(15)$ \\
\hline
\end{tabular}

^Not all patients completed questionnaire.

†Significantly $(\mathrm{p}<0.05)$ different from cognitive therapy (Fisher's exact test).

$\ddagger$ Significantly $(\mathrm{p}<0.05)$ different from score in general practitioner care (Fisher’s exact test).

$\$$ Significantly $(\mathrm{p}<0.05)$ greater than score in amitriptyline/psychiatrist treatment and general practitioner care (one way analysis of variance). general practitioner contact by a third, but the cost of amitriptyline was trivial compared with the cost of the psychiatrist's time.

\section{TREATMENT EVALUATION BY PATIENTS}

Social work counselling was evaluated most positively in terms of meeting needs and helping with problems (table VII). Although therapist contact varied more than 10-fold among the treatment groups, there were no significant differences in how patients rated their satisfaction with the amount of time they had received from their therapist. Only a small minority of patients definitely wanted the same treatment again should they become depressed in the future. Social work counselling was the exception and had a significantly higher score in the global evaluation of treatment than either general practitioner care or antidepressant drug treatment.

\section{Discussion}

In today's NHS the clinical efficacy of a treatment may be compromised if patients do not like it, if it takes too long, or if it costs too much. One in six patients offered amitriptyline from the psychiatrist refused to take it, which is an important reason to study alternatives to drug treatment in the management of depressive illness.

Most patients who gave up specialist treatment received cognitive behaviour therapy, and a similar drop out rate has been recorded in previous studies in primary care. ${ }^{1617}$ Treatment requires the active participation of patients, and it has been suggested that the material circumstances and psychological sophistication of patients have important effects on outcome. ${ }^{17}$ All the patients who dropped out of treatment in the present study were young and from the lower social classes. Social work counselling, a more flexible intervention with a greater emphasis on feelings, was readily acceptable and rated most helpful by patients. Relevant studies of the importance of social factors in the onse ${ }^{14}$ and management ${ }^{12}$ of depressive illness have concerned women, and it was unfortunate that few men were allocated to social work counselling. There was no comparable "drop out" from routine general practitioner care, because this was a policy rather than tightly defined treatment. Clearly further study is necessary, but these findings suggest that making specialist treatments more accessible does not necessarily guarantee their acceptability to depressed patients in primary care.

All specialist treatments involved much longer patient contact, which cost about four times as much as in routine genęral practitioner care. Contrary to our expectation, a treatment that takes a long time can be popular with patients: social work counselling was the most acceptable and positively evaluated of the treatments. Routine general practitioner care took only a handful of appointments, but general practitioners referred some patients to other NHS staff and facilities, which reduced the cost differential to threefold. The cost of drugs prescribed by the general practitioners reduced the cost differential further to twofold. Since the end of the study antidepressant drugs highly selective for serotonin have become more widely used. These drugs are much more expensive than traditional drugs like amitriptyline, and their introduction may have had a marked effect on the cost of antidepressant drugs prescribed. An important difference from ordinary clinical practice that may have affected the analysis of cost is that the diagnosis of depressive illness was confirmed for all patients. This may have reduced the number of medical investigations and referrals made by the general practitioners.

The most important assessment of treatments we 
have left till last. The severity of depressive symptoms declined markedly in all treatment groups, and any differences in clinical efficacy between the specialist treatments and routine general practitioner care were not commensurate with the differences in the length and cost of treatment. This generalisation may not apply to more severely depressed (melancholic) patients, but this requires confirmation in a larger sample of patients. The simplest explanation may be that depressive illnesses treated in primary care are of shorter duration than those referred for outpatient care $^{15} 16$ and usually have a good prognosis anyway. ${ }^{2}$

The design of the study must also be considered in the interpretation of the findings on clinical efficacy. It is probable that the independent raters became aware of treatment allocation before patients completed treatment, although it is hard to predict what effects this might have had on the findings. Confirmation of the diagnosis of depressive illness may have improved the effectiveness of routine general practitioner care, because recognition of depressive illness may be associated with a better clinical outcome and increases the likelihood of being offered treatment from general practitioners. ${ }^{26}$ Even patients who refused to start or continue treatment had been made aware of the diagnosis of depression and it is unfortunate there were no available data on their clinical progress because these may have provided further information about what, if any, additional benefit treatment itself brought. A major aim of the present study was to measure the routine length of the patient-therapist contact involved in each treatment, and so no attempt was made to standardise therapeutic attention among the treatments. Consequently, it cannot be assumed that any slight advantage for one of the specialist treatments depended on the defining characteristics of the treatment rather than the length of therapeutic attention. ${ }^{17}$

Most patients rated the results of their treatment positively, but few said they would want the same treatment again. Perhaps this reflects a dislike of being depressed or fears about the possibility of future episodes. Such fears are realistic because most outpatients who recover from an episode of depression will suffer a recurrence of illness within two years despite continuation treatment with antidepressant drugs. ${ }^{27}$ Depressed patients treated by cognitive behaviour therapy may be less likely to relapse than patients treated with antidepressant drugs alone over one ${ }^{28}$ and two $^{29}$ years after the index episode. The potential longer term benefits of social work counselling have not been assessed. If social work counselling or cognitive therapy helps patients to cope more effectively with the problems that led to their depression this may prevent further episodes of depression. Until we have measured relapse rates after treatment our cost-benefit analysis is incomplete.

This study was funded by the Health Services Research Committee of the Scottish Home and Health Department. We thank Mrs Fiona Barry, Mrs Caroline Blair, Mrs Jane McBean, Mrs Judith Stewart, Mrs Wilma Warwick, and Dr Fiona Zegelman for their work towards the study and Mrs Brenda Thomas for the preparation of the manuscript. We also thank all the general practitioners and their patients who took part in the study.
1 Shepherd M, Cooper B, Brown AC, Kalton G. Psychiatric illness in general practice. 2nd ed. Oxford: Oxford University Press, 1981.

2 Goldberg DP, Blackwell B. Psychiatric illness in study using a new method of case identification. BMf 1970;ii:439-43.

3 Watson JM, Barber GH. Depressive illness in general practice: a pilot study. Health Bull 1981;39:112-6.

4 Porter AMW. Depressive illness in general practice. A demographic study and a controlled trial of imipramine. BMJ 1970;i:773-8.

5 Blashki TG, Mowbray R, Davies B. Controlled trial of amitriptyline in general practice. $B M \mathcal{F} 1971 ; \mathrm{i}: 133-8$.

6 Thomson J, Rankin H, Ashcroft GW, Yates CM, McQueen JK, Cummings $\mathrm{SW}$. The treatment of depression in general practice: a comparison of $\mathrm{L}$ tryptophan, amitriptyline and a combination of $L$-tryptophan and amitriptyline with placebo. Psychol Med 1982;12:741-51

7 Paykel ES, Hollyman JA, Freeling P, Sedgwick P. Predictors of therapeutic benefit from amitriptyline in mild depression: a general practice placebocontrolled trial. F Affective Disord 1988;14:83-95.

8 Johnson DAW. Treatment of depression in general practice. BMF 1973;ii: $18-20$

9 Trethowan WH. Pills for personal problems. BMf 1975; iii:749-51.

10 Lader M. The social implications of psychotropic drugs. $R$ Soc Health $f$ 1975;95:304-5.

11 Tyrer P. Drug treatment of psychiatric patients in general practice. $B M \mathcal{F}$ 1978; ;i:1008-10.

12 Corney RH. The effectiveness of attached social workers in the management of depressed female patients in general practice. Psychol Med 1984;suppl 6.

13 Cooper B, Sylph J. Life events and the onset of neurotic illness: an investigation in general practice. Psychol Med 1973;3:421-35.

14 Brown GW, Harris T. Social origins of depression. London: Tavistock Publications, 1978

15 Sireling LI, Freeling P, Paykel ES, Rao BM. Depression in general practice: clinical features and comparison with outpatients. Br f Psychiatry 1985;147: $119-26$.

16 Blackburn IM, Bishop S, Glen AIM, Whalley LJ, Christie JE. The efficacy of cognitive therapy in depression: a treatment trial using cognitive therapy and pharmacotherapy each alone and in combination. $B r f$ Psychiatry 1981;139:181-9.

17 Teasdale JD, Fennell MJV, Hibbert GA, Amies PL. Cognitive therapy for major depressive disorder in primary care. Br f Psychiatry 1984;144:400-6.

18 Buchan IC, Richardson IM. Time study of consultations in general practice. Edinburgh: Scottish Home and Health Department, 1973.

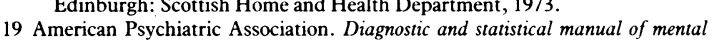
disorders. 3rd ed. Washington: APS, 1980.

20 Beck AT, Rush AJ, Shaw BF, Emery G. Cognitive therapy of depression: a treatment manual. New York: Guildford, 1979.

21 Open University. Advanced educational and social research methods survey project guide DE801. Buckingham: Open University Press, 1985.

22 Hamilton M. A rating scale for depression. I Neurol Neurosurg Psychiatry 1960;23:56-61.

23 Personal Social Services Research Unit. The methodology for costing community and hospital services used by clients of the care in the community demonstration programme. Canterbury: University of Kent, 1989. (Discussion paper 647.$)$

24 Joint Formulary Committee. British national formulary. No 20. London: British Medical Association and Royal Pharmaceutical Society of Great Britain, 1988:123-49.

25 Elkin I, Shea T, Watkins JT, Imber SD, Sotsky SM, Collins JF, et al. The National Institute of Mental Health treatment of depression collaborative research programme: general effectiveness of treatments. Arch Gen Psychiaty 1989;46:971-82.

26 Ormel J, Van Den Brink W, Koeter MWJ, Giel R, Van Den Meer K, Van De Willige G, et al. Recognition, management and outcome of psychological Willige G, et al. Recognition, management and outcome of psychological disorders in prima

27 Glen AIM, Johnson AL, Shepherd M. Continuation therapy with lithium and amitriptyline in unipolar depressive illness: a randomised, double-blind, controlled trial. Psychol Med 1984;14:37-50.

28 Simons AD, Murphy JE, Levine JL, Wetzel RD. Cognitive therapy and pharmacotherapy for depression. Arch Gen Psychiatry 1986;43:43-8.

29 Blackburn IM, Eunson KM, Bishop S. A two-year naturalistic follow-up of depressed patients treated with cognitive therapy, pharmacotherapy and a combination of both. F Affective Disord 1986;10:67-75.

(Accepted 20 Fanuary 1992)

\section{Correction}

Workload of general practitioners before and after the new contract

Several errors occurred in this paper by David Hannay et al (7 March, p 615). In the fifth sentence of the results section of the abstracts the figures for the time spent on general medical service duties are incorrect and should be $40.5 \mathrm{~h}$ in $1990 v 42.5 \mathrm{~h}$ in 1991 . Two errors occur in table IV: in the second column the first figure should be 124, not 1124; and in the final column the asterisk should refer to the third value down $(0 \cdot 001)$, not the fourth. 